\title{
El papel de la publicidad en España en prensa y radio durante el franquismo: el nacimiento de la sociedad de consumo
}

\author{
The role of advertising in Spain in the press and radio during \\ Franco's regime: The birth of consumer society \\ 0 papel da publicidade na Espanha na imprensa e no rádio durante o regime \\ franquista: o nascimento da sociedade de consumo
}

ANA SEBASTIÁN MORILLAS, Universidad de Valladolid, Segovia, España [anaseb@hmca.uva.es]

\section{RESUMEN}

Esta investigación cualitativa examina la influencia de los medios de comunicación social y la publicidad en los hábitos de consumo y estilos de vida de los españoles del franquismo (1939-1975). El análisis de más de 400 piezas publicitarias en prensa y radio, y de entrevistas a expertos en el tema, aporta datos reales, abundantes y novedosos sobre esta materia y las conclusiones permiten reafirmar la idea de que la publicidad, a través de los medios, cambió hábitos de consumo y estilos de vida en los españoles de aquella época, dando paso al nacimiento de la sociedad de consumo.

\section{ABSTRACT}

This qualitative research examines the influence of social media and advertising on consumption habits and lifestyles of the Spanish of Franco's regime (1939-1975). The analysis of more than 400 advertising pieces in the press and radio, as well as of interviews with experts in the subject, brings real, abundant and novel data on this subject and the conclusions allow to reaffirm the idea that-through the media-advertising changed habits of consumption and lifestyles in the Spanish of the epoch, thus arising the consumption society.

Keywords: social media; press; radio; advertising; Franco's regime; consumer habits; lifestyles; consumption society.

\section{RESUMO}

Esta pesquisa qualitativa examina a influência das mídias sociais e da publicidade sobre hábitos de consumo e estilos de vida dos espanhóis durante a ditadura de Franco (1939-1975). A análise de mais de 400 peças publicitárias na imprensa e rádio e entrevistas com especialistas no assunto traz dados reais, abundantes e novos sobre esse assunto, e as conclusões permitem reafirmar a ideia de que a publicidade, através da mídia, mudou hábitos de consumo e estilos de vida do cidadão espanhol da época, dando lugar ao nascimento da sociedade de consumo.

Palavras-chave: mídia social; imprensa; rádio; publicidade; Franco; hábitos de consumo; estilos de vida; sociedade de consumo. publicidad; franquismo; hábitos de consumo; estilos de vida; sociedad de consumo.

Forma de citar:

Sebastián Morillas, A. (2017). El papel de la publicidad en España en prensa y radio durante el franquismo: el nacimiento de la sociedad de consumo. Cuadernos.info, (41), 209-226. https://doi.org/10.7764/cdi.40.1128 


\section{INTRODUCCIÓN A LA ÉPOCA ESTUDIADA}

Tras el fin de la Guerra Civil, España entró en una larga etapa caracterizada por un sistema político singular: el franquismo. Este sistema, que duró hasta 1975 se basó en la concentración de todo el poder político en manos del general Francisco Franco.

España vivía en torno de las cartillas de racionamiento. La carencia de artículos de primera necesidad era tal que se impuso la cultura del sucedáneo. Una de las preocupaciones de los jóvenes en aquella década de los años 1940 era encontrar un apartamento. En el año 1943, eran 50.000 las parejas que buscaban una casa donde poder establecerse. La demanda provocó una especulación exagerada, aumentando el precio del alquiler de 150 pesetas mensuales en 1939 a las 1.000 en 1945 (Marchamalo, 1996, p. 207).

En 1940 se creó oficialmente la Prensa del Movimiento y, por una orden del 1 de mayo de 1941, se la exoneró de la censura previa. La información que ocupaba buena parte de los diarios eran los deportes, la válvula de escape para la situación anteriormente descrita. Pero ni siquiera en esta sección la libertad de los informadores podía ser completa, ya que hubo que ocultar la pasión, los incidentes y hasta las pretensiones económicas de los futbolistas.

Lo mismo ocurría en la radio, para la cual una orden del 6 de octubre de 1939 estableció en todo el territorio la censura previa. Otra posterior, del 7 de marzo de 1941, la extendió a la publicidad, que a partir de ese momento tendría que sujetarse a rígidas condiciones de contenido e incluso de ubicación en los programas, aunque no de proporción con respecto al conjunto de la emisión (Barea, 1994, p. 45).

Estaba prohibido emitir anuncios en los instantes inmediatamente precedentes o siguientes a conexiones con la emisora oficial, ejecución de himnos nacionales, actuación de autoridades y jerarquías o retransmisiones de actos oficiales.

La censura fijó su objetivo fundamentalmente en los contenidos políticos, religiosos y morales. En algunas emisoras, se exigía la presentación de guiones con 48 horas de antelación, o con 24 horas, en el mejor de los casos.

A finales de los años cincuenta, España había dejado de ser un país subdesarrollado para convertirse en una modesta potencia económica. Este factor produjo cambios acelerados en la sociedad, los que tuvieron como consecuencia que las diferencias entre la calidad de vida del campo y de la ciudad se acentuaran. La década de los años 1960 aparecía llena de posibilidades, abierta a transformaciones asombrosas, que respondían a la perspectiva vitalista que dominaba a la sociedad española.

El 15 de marzo de 1966, se aprobó la nueva Ley de Prensa con el fin de canalizar y estimular a la opinión pública española.

La opinión pública empieza a ver, primero con sorpresa, y muy pronto ya con naturalidad, que los problemas reales salen ya en letra impresa. (...) existe una explícita conciencia de cambio. La gente empieza a hablar más claramente y, por lo menos, el miedo tiende gradualmente a desaparecer (Morodo, 1966, p. 12)

En términos políticos, la década de los setenta comienza con un persistente ambiente de rechazo al régimen. La reacción social empieza a notarse en la calle, se empiezan a ver los primeros movimientos de consumidores en España, se organizan asociaciones, jornadas de información, e incluso revistas. El 20 de noviembre de 1975 muere el general Franco: la censura tiene los días contados y la libertad de expresión pasará a ocupar un lugar privilegiado en la escala de valores del país.

\section{MARCO TEÓRICO: LA PUBLICIDAD DURANTE EL FRANQUISMO Y EL NACIMIENTO DE LA SOCIEDAD DE CONSUMO}

Para entender el presente hay que analizar el pasado; es por ello que nuestro objeto de estudio es analizado desde diversas perspectivas y medios como el trabajo de Mercedes Montero (2012), que examina el papel de la publicidad durante el franquismo, en el que afirma que en la década de 1940 la publicidad denunció a la autarquía que estaba hundiendo el país. La de 1950, supo abrir la mente de los españoles hacia productos de consumo y modos de vida habituales en otros mercados. Y desde 1960 hasta el final del franquismo, consiguió que el público asociara los diversos productos con valores muy alejados de la España oficial. Marchamalo, en su libro Bocadillos de delfin (1996), nos muestra los anuncios y la vida cotidiana en la España de la postguerra. Abella (1985, p. 109) pone de manifiesto datos oficiales que cifraban el déficit de viviendas en más de medio millón de casas, y Vázquez Montalbán (1986, p. 42) corrobora que los españoles adquieren una filosofía de la vida cínica reflejada en la canción de la Piquer: "Que no me quiero enterar, no me lo cuentes vecina, prefiero vivir soñando que conocer la verdad". Esta es la realidad del período estudiado.

También hay que mencionar los estudios académicos 
sobre historia de la publicidad, relacionados con el consumo y los medios de comunicación, señalando las aportaciones de González Martín (1996) y Eguizábal Maza (2007), que reflejan que la publicidad es un hecho comercial, social y cultural que permite estimular a los consumidores para que compren un producto o hagan uso de un servicio. Pérez Ruíz (2001, 2003), nos explica la publicidad en España desde el punto de vista de anunciantes, agencias y medios, y Caro (2014), nos ayuda a comprender la publicidad para transformar la sociedad.

Las aportaciones más relevantes sobre la evolución del consumo en España las han desarrollado Luis Enrique Alonso y Fernando Conde (1994), José Castillo (1987) y María Luisa López Vargas (1994), quien explica el paso del consumo tradicional al modelo de consumo moderno.

Con su intervención -especialmente a partir del Plan de Estabilización de 1959-el franquismo no solo construyó las bases económicas de la sociedad de consumo, sino que, como efecto perverso e inicialmente no deseado, generó también unas condiciones culturales, ideológicas y motivacionales óptimas para el desarrollo a lo largo de los años sesenta de un modelo fuertemente consumista. "El consumo es un modo activo de relacionarse (no solo con los objetos, sino con la comunidad y con el mundo), un modo de actividad sistemática y de respuesta global en el cual se funda todo nuestro sistema cultural" (Baudrillar, 2009).

En la década de los años 1950 se produjo una serie de cambios tanto en el contexto internacional de España como en la misma sociedad del país, que fueron determinantes para el despegue de la sociedad de consumo. Destaca el aumento considerable que sufrió el sector industrial, paralelo al descenso del sector agrícola, cuya población sectorial activa cayó de 51,9\% en 1940 a $41,7 \%$ en 1960, y un quinquenio más tarde se desplomó a $34,8 \%$. En aquellas mismas fechas, la industria aumentó su participación de 24\% a 31,7\%, llegando a 33,4\% en 1965 (INE, 1965, p. 470; 1970a, p. 289).

En el plano del consumo esto se manifiesta en un aumento de subsistencias, por lo que la renta per cápita aumentó también en esos años. Sin embargo, entre los años 1940 y 1950 se produjo un descenso de la renta per cápita debido a la lenta recuperación de la posguerra. La reducción del nivel de vida y consumo se reflejó en un crecimiento de los casos de malnutrición. En el año 1950 se alcanzó el valor más bajo de renta per cápita en toda la década, 9750 pesetas (Alonso \& Conde, 1994, p. 130). Sin embargo, se aprecia un aumento considerable de renta per cápita desde 1940 a 1963: pasó de 11.042 pesetas a 20.557 pesetas, casi el doble (Castillo, 1987, p. 54).

El nacimiento de la sociedad española de consumo se caracterizó por un fuerte desarrollo de las nuevas clases medias. La memoria reciente y muy presente del hambre hizo que la sociedad de la subsistencia pasara a protagonizar un consumo acelerado en la década de los sesenta.

El consumo de productos y de bienes más inmediatos e imprescindibles, va a 'marcar' la fuerte voracidad del consumo de estos años. De esta forma, el saciarse y no alimentarse, la mera posesión como distinción (más allá de la calidad y funcionalidad de los productos), la compra, a-crítica (de hecho llega a estar de moda en la publicidad de aquellos años el uso continuo de expresiones que nadie entendía pero que connotaban lo extranjero, lo moderno, etc.), se conforman en esos años como características centrales de nuestro modelo de consumo y de consumidores (Conde, 1994, p. 147)

También se refleja el cambio social que está viviendo España en las cifras que muestran la escasez de alimentos y recursos en los años posteriores a la Guerra Civil. A lo largo de los años, se fueron introduciendo nuevos productos en el mercado, se produjo un crecimiento de la economía nacional (aún leve, pero que permitió a muchos salir de la más absoluta pobreza) y el gasto en las capitales de provincia se disparó. Es así que, de acuerdo a los datos de la Dirección General de Estadística (1943, pp. 1145-1146) y del INE (1960, p. 598) el índice general de consumo entre los años 1939 y 1959 (con base en julio de 1936 = 100) aumentó de 153,6 a 866,7, siendo los casos más notorios los de alimentación $(177,7$ a 1141,8) y vestuario $(190,1$ a 1094,9).Desde el punto de vista del consumo son años en los que comienzan a introducirse productos y marcas de manera minoritaria, aunque lo más destacable es que traen consigo expectativas de un acceso fácil a su consumo. Será en los años sesenta cuando se observe un inicio de la recuperación económica, que será más evidente conforme la década llegue a su fin. Fiel reflejo de esta dinámica será la adquisición por parte de las familias españolas de todo tipo de productos imposibles de comprar hasta entonces (desde electrodomésticos hasta automóviles); por ejemplo, en 1960 un 4\% de la población española disponía de frigorífico y en 1966 ya era el 28\% de la población (Andrés, 1968, p. 39).

Los españoles alcanzaron un nivel de vida del que disfrutaron con frenesí para resarcirse de los malos años 
pasados. La nueva clase media imitó en su forma de vida a la alta burguesía o a la aristocracia. Se luchaba por tener un apartamento más grande, más céntrico y mejor equipado. Abella (1990, p. 110) comenta que las atareadas amas de casa (de las cuales, al final de la década de los sesenta, el 25\% también mantiene un trabajo fuera del hogar) ven en estos nuevos utensilios una solución a interminables horas en la cocina, mientras que el resto de la familia, especialmente el marido, se queja de que las cosas no saben igual.

En pleno despegue, la economía española entró en un período de recesión. El sueño monetario se tambalea y el ciudadano medio deja de plantearse problemas sociales, políticos o de cualquier otra índole frente a la preocupación (mucho más cercana) de llegar a fin de mes. En 1969 el salario mínimo era de 102 pesetas diarias (3.162 pesetas al mes) (Abella, 1990, p. 112).

A principios de la década de los setenta, los ciudadanos españoles caminaban aceleradamente hacia una sociedad de consumo de masas bien definida. El ciudadano, plenamente integrado en su rol de consumidor, elegía en qué gastar su presupuesto más allá de las necesidades básicas. Se produjo un crecimiento en la adquisición de equipamientos básicos del hogar, y se desarrollaron pautas de consumo y de compra de nuevos productos. Puede que unas vacaciones en la playa no estuviesen a su alcance, pero las comodidades de las que disponía en su hogar cada día eran mayores, cada vez había más hogares con cuarto de baño y agua caliente: en 1970 las viviendas familiares con agua caliente en propiedad y pagada eran 154.817 (INE, 1970b, p. 55). También se produjo un espectacular crecimiento en el porcentaje de viviendas con frigorífico, que en 1975 era de 73,7\% (INE, 1975, p. 86).

En esos mismos años la inversión publicitaria en España sufrió un revés importante, pasando de 17 millones en 1968 a 19 millones en 1970 (su punto máximo). En el año 1971 cayó hasta los 18.310.500.000 de pesetas, un retroceso general del que tan solo se salvó la televisión (Asociación para la Investigación de Medios de Comunicación, 1998, p. 30).

Aun así, seguían llegando nuevos productos del extranjero que entraban ahora en un nuevo período con más fuerza. Era la nueva generación de neveras, cosméticos y lavadoras, cuya verdadera evolución se produjo en el mundo de las ideas, ya que en muchos casos su único cambio era presentar una serie de nuevos atributos del producto. Esto se observa de forma clara en las lavadoras, que se convirtieron en símbolos de modernidad, casi del futurismo, formando parte de un panorama utópico en el que las máquinas nos librarían de las más penosas labores del hogar.

Los españoles eran ya consumidores plenamente formados, que pasaron de comprar y usar productos por su utilidad a adquirirlos en función de lo que significaban. "Las cosas que compra la gente adoptan significados personales y sociales además de sus funciones propias", explica María Isabel Martín (2002, pp. 43-44), y recuerda: "Los productos son vistos como objetos psicológicos, como símbolos de atributos personales". Lógicamente, tan solo las clases acomodadas podían permitirse el lujo de dedicar su dinero a comprar símbolos, abriendo el camino a la nueva y amplia clase media burguesa, de acuerdo a Orizo (1977, p. 123).

La publicidad comienza así a jugar un papel fundamental de cohesión social en la nueva sociedad de consumo.

El nivel de vida español se afirma todavía sobre la base de poseer más que de disfrutar, de consumir los productos sucedáneos de la nueva civilización de fabricación masiva con el privilegio de disponer todavía de algunos de los servicios de una sociedad tradicional. El nivel de vida destaca en España -para algunos- por tener servicio doméstico. Se compran más libros de los que se leen y se compra un apartamento de vacaciones, aunque apenas se goce de él (De Miguel, 1973, p. 25).

También hay que añadir que en muchos casos la compra era más del símbolo que del producto. Se buscaba tener una lavadora, aunque no fuese la mejor. El caso era evitar que la vecina comentara que aún lavábamos a mano. Pedir un consumo de mayor nivel quizá sea demasiado, cuando se habla de la penuria económica que aún sufrían muchos españoles. En definitiva, se instaló antes el concepto de sociedad de consumo que su realidad.

El gasto destinado a alimentación, vestuario u ocio también cambió. La llegada de nuevos productos al mercado supuso una restructuración del presupuesto. En especial, la partida de gastos diversos aumentó considerablemente, de 3711 pesetas en 1967 a 7426 pesetas en 1974, lo que demuestra que era una sociedad en la que las necesidades básicas estaban cubiertas en gran medida (INE, 1978, p. 308).

Puede considerarse a los españoles de esa época como consumidores adultos, en el sentido de que tenían experiencia a la hora de valorar entre diferentes ofertas, y compraban y usaban productos no por sus posibilidades o prestaciones, sino por lo que significaban. La década de los setenta llegó así entre claroscuros, con la definitiva consolidación del modelo de consumo español 
descrito en los planes de desarrollo: un modelo agresivo, desigual, cuyas disfunciones y desajustes perduraron durante un buen número de años.

\section{METODOLOGÍA}

La metodología utilizada consistió en el análisis de más de 400 piezas publicitarias mediante un cuestionario que refleja los diferentes ítems relacionados con la publicidad, los aspectos sociales y la ideología.

Los periódicos escogidos para el análisis de los anuncios fueron el ABC de Madrid y La Vanguardia Española, ya que en estos años eran los de mayor tirada y difusión según la OJD de 1965 (194.000 y 203.000 difusión media, respectivamente) (Barrera, 1992, pp. 453-454). En lo referente a la prensa diaria, se pueden establecer dos grandes etapas determinadas por el marco legal a lo largo del período franquista. La primera, entre 1939 y 1966, es un período extenso, pero necesario para el estudio, ya que la Ley de Prensa estuvo vigente hasta 1966, y conllevaba una censura previa para todas las publicaciones periódicas. Por ello, el análisis de toda la publicidad de los medios impresos se rigió por los mismos mecanismos. En esta etapa se analizaron un total de cincuenta anuncios en cada uno de los periódicos seleccionados

La segunda etapa comienza en el año 1967 y abarca hasta 1975. En este período la censura dejó de aplicarse a las publicaciones periódicas después de que las cortes franquistas aprobaran, el 15 de marzo de 1966, una nueva ley reconociendo la libertad de expresión en medios impresos y eliminando la censura previa; los medios comenzaron entonces a sentirse libres de publicar contenidos impensables poco tiempo atrás. Para esta etapa se escogió el mismo número de anuncios que en la anterior -cincuenta por medio, 100 en total-, para que los resultados y conclusiones pudieran ser comparables.

Para la radio, la primera etapa comprende entre 1939 y 1959, un período extenso por una doble razón: por un lado, las canciones comerciales (pues en esta época aún no puede hablarse de cuñas publicitarias) tuvieron una evolución muy lenta, y por otro, fue una época difícil, llena de penuria, en la que la radio fue el espejo fiel de lo mucho que los españoles habían perdido en los años anteriores, por lo que merece ser estudiada con detenimiento. A pesar de que el nacimiento de la cuña como tal puede fecharse alrededor de 1949, el escaso número que se ha conservado hasta nuestros días hace que solo podamos contar en el análisis con canciones comerciales, las únicas 110 piezas publicitarias existentes en la actualidad. La segunda etapa abarca los años 1960 a 1975. Es la época en la que la cuña se afianza como el formato publicitario radiofónico estándar, con unas características casi idénticas a las actuales. Es la edad de oro de la radio. Por primera vez el análisis contará con cuñas publicitarias, las primeras que se conservan. Las 100 cuñas que corresponden a la muestra de esta etapa son las únicas en buen estado a las que la investigación pudo acceder.

Con el objetivo de seguir un criterio unívoco, el trabajo de campo realizado se refleja en una ficha de análisis, de elaboración propia, que recoge los mismos ítems centrales, aunque por las particularidades de cada medio se ha requerido la supresión o la incorporación de otros nuevos (tabla 1).

En los anuncios en prensa se suprimen los ítems 5, 6,7 y 8 y se incluyen dos apartados (tabla 2).

El trabajo de campo fue suficiente para conseguir una visión global y multidisciplinar del objeto de estudio, pero se consideró necesario recabar información adicional de distintas fuentes, que completó los resultados del trabajo de campo y, en muchas ocasiones, fue clave para entender los resultados del análisis. Por ello, se realizaron 21 entrevistas personales a diferentes profesionales del sector de la época estudiada: directores creativos, ejecutivos de agencias de publicidad, jefas de publicidad de emisoras de radio, presidentes de agencias de publicidad, directores de estudios publicitarios, directores de productoras y técnicos de sonido, directores creativos de emisoras de radio, locutores publicitarios, actrices de doblaje y profesoresinvestigadores expertos en la materia. La selección y realización de las entrevistas llevadas a cabo con motivo de esta investigación responde a tres intereses principales: en primer lugar, alcanzar una impresión del objeto de estudio desde diferentes puntos de vista, escogiendo cuidadosamente a los entrevistados para que representaran a los diferentes colectivos de profesionales que colaboran en el proceso publicitario. En segundo lugar, acceder a información de primera mano, en muchas ocasiones inédita, sobre el objeto de estudio y, por último, la importante aportación que estos entrevistados realizan a la investigación presentada para reforzar el aspecto más sensible de la relación publicidad-consumidor. También se consultaron libros, informes y anuarios del período analizado, así como revistas especializadas. Todo ello permitió que la investigación pudiera establecer conclusiones fiables sobre el objeto de estudio. 


\begin{abstract}
1. Categorías de producto: alimentación, hostelería, medicinas, almacenes/tiendas, electrodomésticos, productos electrónicos, instituciones, cultura, bebidas alcohólicas, bebidas sin alcohol, limpieza, medios de comunicación, medios de transporte, complementos, hogar, otros.
\end{abstract}

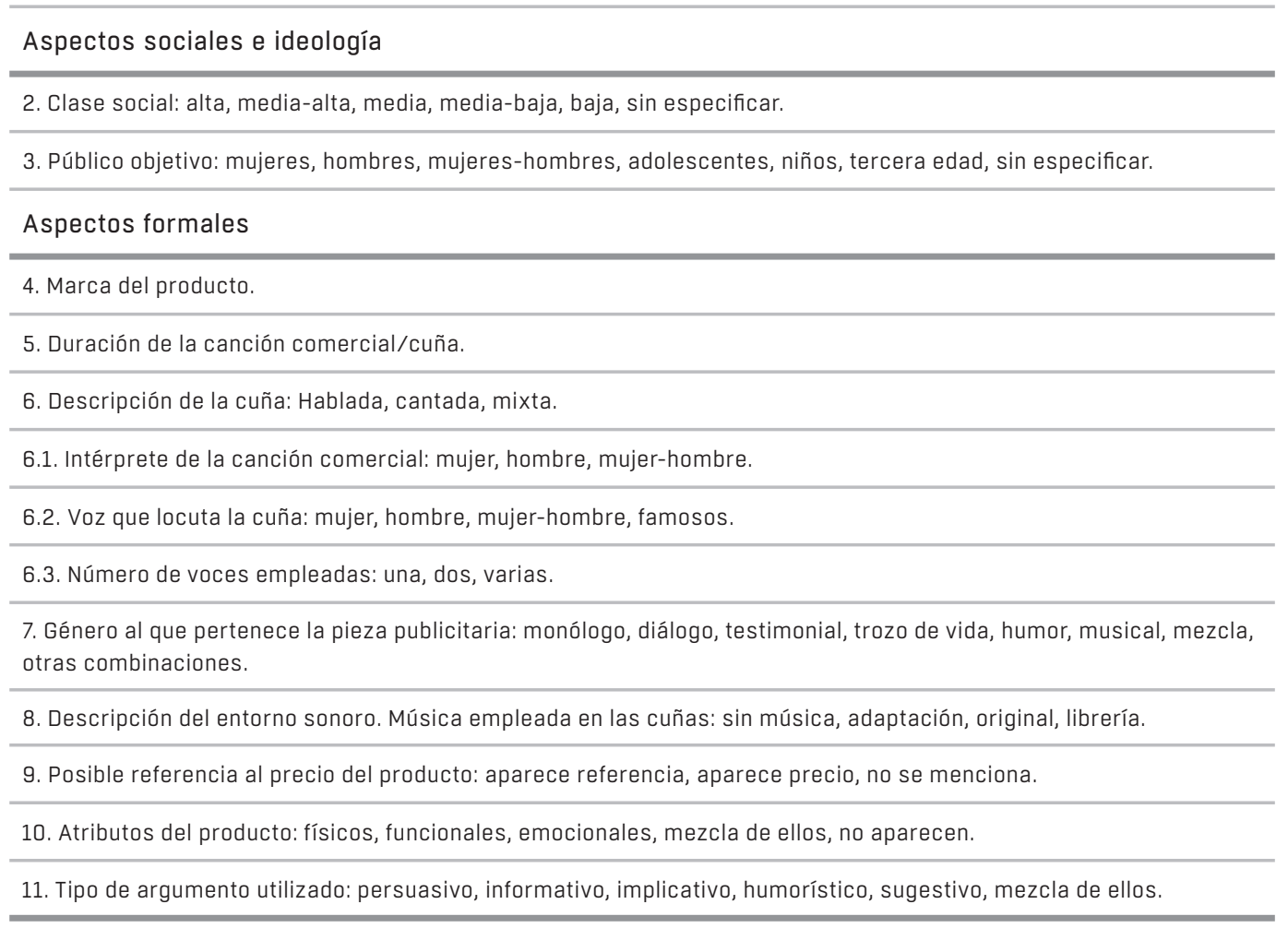

Tabla 1. İtems para el análisis en radio

Fuente: Elaboración propia.

1. Tipo de formato: página entera, media página, doble página, 2/3 de página, 1/8 de página, 1/4 de página, otros.

2. Situación en el periódico: portada, contraportada, página interior de portada, página interior de contraportada, otras.

Tabla 2. İtems para el análisis en prensa

Fuente: Elaboración propia.

\section{RESULTADOS}

PRENSA: PRIMER PERÍODO 1939-1966. ABC Y LA VANGUARDIA ESPAÑOLA

Se analizó un total de 100 anuncios pertenecientes a esos años, 50 por cada periódico. En el análisis se observa una distinción clara entre los dos periódicos analizados: en La Vanguardia,los productos que más se anunciaban eran los de higiene y belleza (22\%), medicinas (18\%), bebidas alcohólicas (10\%) y electrodomésticos (8\%), mientras que en $\mathrm{ABC}$ eran las bebidas alcohólicas (26\%), higiene y belleza (22\%), joyas (12\%) y electrodomésticos (6\%). En los dos periódicos, las mismas categorías de producto coinciden en los primeros puestos, aunque no en el mismo orden. Existen dos categorías que parecen casi exclusivas de cada publicación. En el caso de La Vanguardia son las medicinas, que apenas aparecen en $\mathrm{ABC}$, y en este último son las joyas (casi en su totalidad relojes de lujo) las que aparecían entre las más anunciadas, mientras que en el diario catalán tenían una aparición mucho menos relevante. 


\begin{tabular}{lcccc} 
Actividad profesional: textil & 1940 & 1952 & 1964 & 1969 \\
\hline Hombres & 13,96 & 17,34 & 22,89 & 49,09 \\
\hline Mujeres & 6,81 & 11,46 & 16,03 & 27,89 \\
\hline
\end{tabular}

Tabla 3. Remuneraciones máximas por jornada (en pesetas)

Fuente: Dirección General de Estadística, 1943, p. 1179;

INE, 1955, p. 524; 1965, p. 292; 1970a, p. 285

Resulta evidente que no todo el mundo podía acceder a los productos anunciados. Los salarios no iniciaron su despegue hasta el final de la década de los sesenta, como se puede observar en la tabla 3.

La situación económica nacional era precaria, por lo que resulta evidente en la mayoría de los casos de anuncios analizados que estos se dirigieran a un receptor adinerado, tanto en el diario $\mathrm{ABC}$ como en La Vanguardia.

La mayoría de los productos anunciados estaban destinados a mujeres, aunque en el diario ABC el porcentaje era menor debido al gran número de anuncios de bebidas alcohólicas de alta graduación.

El llamamiento explícito al ama de casa trataba de conformar un nuevo modelo de mujer responsable de su hogar que sustituyera al ama de casa tradicional. La transformación se produciría gracias a los nuevos equipamientos de consumo, una nueva vida tranquila, libre y con tiempo suficiente para salir de paseo y de compras, dejando atrás su anticuada y penosa vida anterior. Así se refleja en el siguiente ejemplo, un anuncio de lavadoras BRU publicado en La Vanguardia en 1957 :

No le costará convencerle.

Su marido no le negará un elemento auxiliar tan necesario para el hogar.

Insinúele usted su deseo y las ventajas que les va a reportar: menos trabajo para usted, menos molestias, más comodidad en el hogar, más limpieza y él, mejor atendido.

Bastará esto para que su marido le regale una lavadora BRU

(Viernes 7 de junio de 1957, p. 32).

Mientras que la publicidad de $A B C$ empleaba de manera más evidente una comunicación más emocional (24\%) -en la que primaba la elegancia, la distinción, la exclusividad-, los anuncios en La Vanguardia se dirigían a un público con posibilidades económicas más modestas, por lo que sobresalían los atributos funcionales (30\%), la explicación de las ventajas del producto en cuanto a calidad, durabilidad, ahorro, y su origen nacional. Tras unos años de escasez casi absoluta de los más elementales productos de supervivencia, comenzaban a introducirse en el mercado nuevos productos y marcas, que suponían la promesa de un mañana mejor. Esto se traduce en el uso de argumentos persuasivos (50\%) con toques informativos (16\%), en el caso de los anuncios de La Vanguardia, mientras que en las páginas de $A B C$ ese argumento persuasivo (34\%) con frecuencia se acompañaba de imágenes sugerentes y argumentos emocionales y sugestivos (20\%). Un buen ejemplo de argumento persuasivo se encuentra en la crema Kaloderma Gelee:

¿Un cigarrillo, señorita?

Ud. agradece el amable ofrecimiento. Pero... ¿no sentiría desazón si a la tenue luz del fósforo su mano apareciese ajada?

Unas manos bien cuidadas la darán siempre seguridad en sí misma y demostrarán su personalidad y distinción.

Cuide sus manos con "Kaloderma Gelee".

Un breve masaje antes de acostarse, durante un minuto, las devolverá toda su frescura y encanto.

Adquiera enseguida un tubo de "Kaloderma Gelee" y comience hoy mismo este sencillo tratamiento de belleza.

(Sábado 23 de enero de 1954, p. 2).

El precio del producto no aparecía en la mayoría de los anuncios de ambos periódicos, siendo mencionado solo en un 6\% de ellos. Estos anuncios se publicaban principalmente en la página interior de portada y contraportada, los dos lugares más deseados por los anunciantes en ambos periódicos. En el caso de ABC, en particular, era a toda página. En este sentido, La Vanguardia tuvo una evolución a lo largo de los años desde formatos de 1/4 o 1/8 de página hasta alcanzar definitivamente la página completa. Por otro lado, la censura no dejaba pasar ninguna oportunidad de 
prohibir o corregir textos publicitarios: los censores controlaban desde el espacio máximo que podía dedicar el periódico a la publicidad hasta cada palabra de los anuncios publicados.

Los resultados muestran que la sociedad española de consumo forjada en la década de los sesenta nació con deseo de gastar, como efecto de los años de penuria y de escasez vividos en los últimos veinte años.

\section{RADIO: PRIMER PERÍODO 1939-1959}

Se analizó un total de 110 canciones comerciales. Estas ofrecían una doble solución a sus oyentes: anímica y financiera. La publicidad de posguerra oscilaba entre la alegría oculta bajo el maquillaje del payaso triste y la necesidad de seguir viviendo a pesar de la escasez. En la época del racionamiento, al que no se sujetaban las bebidas alcohólicas, los productos más anunciados en la muestra eran los de higiene y belleza (27,9\%), seguidos de los de limpieza (19\%). Casi la totalidad de las canciones comerciales de esta última categoría pertenecen a insecticidas. Había una variada gama de molestos insectos a exterminar. La publicidad ofrecía a través de las ondas mayor cantidad de marcas con efectos asegurados:

Presurosas y dañinas abandonan su covacha y a despensas y cocinas, cautas y ladinas van las cucarachas.

Pero Doña Inés, con el Cucar-ex, espolvoreó por los rincones

Es mujer feliz, pues las logra ver muertas tripa arriba y a sus pies

(Década de 1950 (AAVV, 1993, p. 153)).

Los almacenes y tiendas (9\%) eran también anunciados con frecuencia en las canciones comerciales de esa época, sobre todo destacando sus bajos precios y los pagos a plazos, que eran un valor añadido, como refleja la siguiente marca:

No se ponga usted delante

¡Pero calla, si es Laureano!

¿Qué te trae por esta fila

Nada chico, que me caso, y me compro aquí los muebles que son buenos y baratos. Además, con la ventaja de que los pagos a plazos, sin fiador, sin entrada y sin límite. Un regalo que hacen los muebles Ramón...

...Muebles Ramón son mi ilusión porque son buenos, son bonitos y baratos.

(Década de 1940 (AAVV,1993, p. 196))
La mitad de las canciones comerciales analizadas no se dirigía expresamente a una clase social definida. La otra mitad buscaba, por un lado, a los sectores más modestos y, por otro, hacía un llamado al consumidor pudiente. Un caso claro fue el de las muñecas, que durante estos años fueron un elemento de distinción social. En este ambiente artificial, de alegría forzada pese a las penalidades, la posesión de muñecas de lujo como la Mariquita Pérez o Lolita permitía a sus poseedores, aun habiendo sacrificado más de lo posible en ellas, mantener las apariencias frente al vecindario.

Lolita, Lolita, la muñeca fina y cara
Que a las niñas les depara
Todo un mundo de ilusión.
El peinado y los vestidos de Lolita
a las damas les produce admiración,
Y por eso colocada en mil posturas
en la casa es la mejor decoración.
Tendré traje y zapatillas, y pijama y delantal,
Y maletas y uniforme y hasta un cuarto colosal
(Década de 1940 (AAVV, 1993, p. 210)).

Un capricho caro que no estaba al alcance de la mayoría de los consumidores, según los datos de la tabla 4.

Es importante destacar que la estructura social de la España de la década de 1940 era prácticamente la misma que existía antes de la Guerra Civil, lo que la alejaba de una moderna sociedad de consumo de masas, especialmente porque la España de los años cuarenta era básicamente agrícola. Con esos sueldos, parece realmente difícil comprar una muñeca Mariquita Pérez, que comenzó a venderse a 95 pesetas de las de entonces -lo mismo que costaba un traje a medida-, mientras que la clásica pepona podía adquirirse por 5 pesetas (Marchamalo, 1996, pp. 114-115).

Nuevamente, casi en la mitad de las piezas analizadas el público al que se dirigían los mensajes publicitarios eran las mujeres, con un matiz importante: aparecen por primera vez anuncios dirigidos a niños $(9,1 \%)$. Las marchas militares son el estilo musical más usado, por amplio margen (22\%), en estas canciones comerciales, seguido del pasodoble español (14,2\%). Los ritmos marciales eran para productos nacionales, con sello español, como coñac, tintes o sucedáneos de café.

En las canciones comerciales se prescindía cada vez más del corsé que imponía el tema musical para poder explicar libremente las virtudes del producto. 


\begin{tabular}{lcccc} 
& \multicolumn{2}{c}{ Máximos } & \multicolumn{2}{c}{ Mínimos } \\
Actividad profesional & Año 1940 & Año 1952 & Año 1940 & Año 1952 \\
\hline Textil: hombres & 13,96 & 17,34 & 9,15 & 13,75 \\
\hline Vidrio y cristal: hombres & 15,98 & 21,70 & 10,29 & 13,50 \\
\hline Agrícolas: hombre & 12,10 & 16,30 & 7,77 & 10,40 \\
\hline
\end{tabular}

Tabla 4. Remuneraciones nominales máxima y mínima por jornada (en pesetas)

Fuente: Dirección General de Estadísticas, 1943, p. 1179; INE, 1955, p. 524.

\begin{tabular}{lcc} 
Agrupaciones & Año 1967 & Años 1973-1974 \\
\hline Alimentación & 7.778 & 10.097 \\
\hline Vestuario y calzado & 2.077 & 1.651 \\
\hline Vivienda & 1.969 & 3.523 \\
\hline Gastos de casa & 1.688 & 3.548 \\
\hline Gastos diversos y vacaciones & 3.711 & 7.426 \\
\hline Consumo total & 17.223 & 26.245
\end{tabular}

Tabla 5. Evolución del consumo anual medio por persona según agrupaciones de gasto. Conjunto nacional (en pesetas)

Fuente: INE, 1978, p. 308.

Si bien los temas solo cantados eran los más numerosos (68\%), aparecen las primeras canciones comerciales solo habladas. Mantienen en líneas generales la estructura de la típica canción comercial, pero sus intérpretes anteponen el fondo a la forma. El objetivo no es ya crear una pieza musical en la que se incluya un contenido comercial, sino que se busca no romper con la estructura musical a la que está acostumbrado el público, asegurándose a la vez de que este reciba claramente el contenido persuasivo del mensaje.

Los atributos emocionales $(23,7 \%)$ son los que se encuentran con más asiduidad, dentro de un argumento persuasivo (52,7\%), aunque -como era de esperartambién hay una presencia del argumento humorístico $(11,8 \%)$, destacable por dos razones: porque responde a la función catártica frente a las penas cotidianas y porque su utilización crecería a partir de entonces, siendo cada vez más empleada.

Los estereotipos que se pueden encontrar en la publicidad de los años cuarenta y cincuenta tienen un origen decididamente popular. Los personajes que aparecen representan su papel tal y como deben hacerlo, según las reglas de la sociedad en la que se enmarcan. Detalles como el papel reservado a la mujer en este estilo de vida quedan claramente reflejados, así como la división social evidente existente en la sociedad, lo que provoca curiosos contrastes en los mensajes analizados.

\section{PRENSA: SEGUNDO PERÍODO 1967-1975. ABC Y LA VANGUARDIA ESPAÑOLA}

Se analizó un total de 100 anuncios pertenecientes a esos años, 50 por cada periódico. En los últimos años de la década de los sesenta y primeros de la de los setenta, los ciudadanos españoles caminaban aceleradamente hacia una sociedad de consumo de masas bien definida. Esto se refleja claramente en el análisis de la publicidad de los periódicos seleccionados.

En el diario La Vanguardia existía una mayor variedad de publicidad. La categoría principal era medios de transportes (28\%), seguida de electrodomésticos (10\%) y joyas ( $10 \%$, siendo todos los artículos relojes). La categoría "otros" engloba anuncios referidos a autoradios, sistemas de calefacción y máquinas de fotos. El caso de $\mathrm{ABC}$ es distinto. En su publicidad no se encontró tanta variedad de productos. Básicamente, son los mismos de la etapa anterior, pero cambiando su orden en el ranking de los más habituales. En las páginas analizadas apenas tiene representación la categoría medios de transporte (que pasa a engrosar el apartado de varios), a pesar de que en esos años era una industria en auge, 
junto con la de los electrodomésticos para el hogar. Los productos más anunciados según el estudio eran joyas (30\%, siempre anuncios de relojes), seguidas de bebidas alcohólicas (22\%) e higiene y belleza (14\%).

Esta llegada de nuevos y variados productos al mercado supuso una reestructuración del plan de gastos, en la que salía perjudicada la cantidad destinada a lo más elemental (ropa y alimentos) a favor del ocio y los gastos diversos, lo que se observa en la tabla 5 .

Los lectores del diario madrileño pertenecían principalmente a la clase alta (78\%), por lo que no es de extrañar que la mayoría de los anuncios se dirigieran a la sociedad más adinerada de la época. Solo las clases acomodadas tenían la capacidad de comprar símbolos, en vez de productos, aunque pronto serían seguidos por la gran clase media. En el análisis se encontró que el diario La Vanguardia publicaba una buena cantidad de anuncios ofertando automóviles de clase media, junto a numerosos anuncios de otros productos en los que se menciona la facilidad de financiación o pagos aplazados.

\section{¡Sí a Mini!}

Mini aumenta su potencia y mantiene su miniprecio y consumo. Para que puedas adelantar todavía con más seguridad...

(...) Mini hace algo que solo podía esperarse de un coche tan generoso: aumentar su potencia, pero aumentar su miniprecio y consumo.

(...) Además, Mini se presenta en nuevos y brillantes colores: amarillo, limón y tabaco. Mini se renueva, sin cambiar su estilo único. Para que puedas gritar todavía más alto su "Sí a Mini”. Desde 92.700 hasta 113.100 pesetas. También financiación.

(Miércoles 3 de abril de 1974, p. 2)

Aunque hace referencia al precio como argumento de venta, no resulta nada habitual que este aparezca en los anuncios, ni siquiera que se haga mención, por eso en el $80 \%$ de las cuñas analizadas no se refleja el precio del producto. Cada vez más la publicidad se va dirigiendo indistintamente a hombres y mujeres, tanto en el ABC (40\%), como en La Vanguardia (36\%), debido a la gran variedad de productos que aparecen en el mercado. Merece la pena destacar que todos los anuncios analizados, en ambos periódicos, son a página completa. Los anunciantes insertaban su publicidad principalmente en la contraportada (56\%) y en la página interior de portada (42\%). Los productos se adornaban con todo tipo de atributos atractivos y deseables, pero una vez que el producto perdía su valor de novedad para el público, había que vestirlo con nuevos atributos. Así, se observa que el término nevera da paso a frigorífico, como en el siguiente anuncio de La Vanguardia:

Ellas supieron elegir...

Para saber comprar, hay que mirar el precio y además, tener en cuenta que aquello que se compra sea perfecto, técnico, práctico, funcional y rentable.

Por eso, ellas supieron elegir. Por eso, eligieron el frigorífico más perfecto, técnico, práctico, funcional y rentable: LEONARD.

(...) Compare, compruebe, vea de cerca y toque la calidad de un Leonard.

REINA PARA TODA LA VIDA CON... LEONARD,

... Señor del frío.

(Jueves 9 de mayo de 1968, p. 79)

En el diario catalán aún se encuentran numerosos atributos físicos y funcionales (30\%), como sucedía en la etapa anterior. $\mathrm{ABC}$, por el contrario, mostraba anuncios con una importante carga emocional (34\%), que sugerían estilos de vida y ambientes en los que enmarcar el producto, normalmente de lujo. Se observa que muchos anunciantes comenzaron a apelar a nuevos valores, que se alejan de la durabilidad, economía o ahorro a favor de abstracciones como la modernidad. Todo era moderno: desde el último modelo de automóvil hasta una lavadora que hacía la colada sola. Se puede considerar a los españoles que vivían en esta época como consumidores adultos, es decir, con experiencia a la hora de valorar entre diferentes ofertas y que compraban y usaban productos no por sus posibilidades o prestaciones, sino por lo que significaban. Se habla del consumo simbólico.

La tradición como argumento de ventas parece más justificada en el siguiente caso publicado en La Vanguardia, coincidiendo con el décimo aniversario del nacimiento del whisky nacional DYC, y emplea la imagen del acueducto de Segovia para que el producto parezca aún más añejo:

DYC. Un noble whisky criado y envejecido al lado de piedras milenarias. Ahora a los diez años de su nacimiento tiene más vejez, más sabor, más calidad.

¡Compruébelo!

DYC, EL VIEJO WHISKY ESPAÑOL

(Jueves 4 de diciembre de 1969, p. 2)

Por eso en $\mathrm{ABC}$ es habitual encontrar argumentos sugestivos (40\%) y sugestivos-implicativos (20\%), mientras que en La Vanguardia son más numerosos los persuasivos (34\%) y persuasivos-implicativos (16\%). Deesta manera, se forma un cuadro general coherente, en el que 
quedan marcadas claras diferencias en cuanto al tipo de lectores de uno y otro periódico y la forma en la que el anunciante intentaba llegar hasta ellos en esta etapa.

La década de los setenta llegará entre claroscuros, con la definitiva consolidación del modelo de consumo español descrito por los planes de desarrollo: un modelo agresivo, desigual, cuyas disfunciones y desajustes perdurarán aún durante un buen número de años.

\section{RADIO: SEGUNDO PERÍODO 1960-1975}

Se analizó un total de 100 cuñas radiofónicas. Por primera, vez se analizan cuñas, los primeros documentos sonoros de este tipo que han sobrevivido.

El consumismo, palabra desconocida en España hasta la década de los sesenta, provoca interesantes cambios en la dinámica observada hasta el momento en los datos del análisis. Esto se debe al aumento de la renta per cápita, desde los años 1940, que era de 11.042 pesetas, hasta 1963, con 20.557 pesetas, más del doble (Castillo, 1987, p. 54). El nuevo modelo de consumo hace que nuevos anunciantes decidan invertir en radio, por lo que en el análisis aparecen dos nuevas categorías de productos: medios de comunicación y medios de transporte. Esta última será especialmente relevante, ya que el sector de los automóviles supuso fuertes inversiones en publicidad y representaba, para una buena parte de la población, éxito, poder social y económico. Por eso, marcas como Chevrolet, Buick, Opel, Renault, Simca o Ford anuncian, por primera vez para el público español, sus virtudes en carretera:

Sobriedad en el diseño y clásico esplendor. Ni por mucho más dinero compra un carro mejor de cristales panorámicos y poderoso motor. Movimientos de gacela, de color es un primor y mucho más económico. En su clase es el mejor. Es el Buick del 59.

(Década de 1960, archivo personal)

Las tres categorías con mayor número de piezas en la etapa anterior (higiene y belleza, limpieza y almacenes/tiendas) aparecen ahora en las últimas posiciones. La publicidad cambió con la sociedad, y debido a que el consumidor adquirió una capacidad económica impensable diez años atrás, podía permitirse pensar en comprar un coche o preferir una determinada marca de producto. Junto a los automóviles extranjeros llegaron las agencias de publicidad americanas, solo un elemento más de las novedades a las que va a asistir la sociedad en general y la publicidad en particular.

En esta etapa, el mayor número de piezas publicitarias anunciaban bebidas sin alcohol (18\%), alimentación
(17\%), medios de transporte (12\%), bebidas alcohólicas (9\%) y medios de comunicación (8\%), mientras que el $36 \%$ restante corresponde a una variedad de productos.

En un primer momento, el consumismo español estuvo marcado por su carácter cuantitativo, producto de la situación de precariedad de la que procede. La época anterior, de pobreza y hambre, debía ser olvidada con la mayor rapidez, por lo que los nuevos consumidores gastaban de manera voraz. Esta tendencia en el consumo varió en cuanto los ciudadanos tuvieron la experiencia suficiente y dedicaron más porcentaje de los ingresos a otras categorías más allá de la alimentación, por ejemplo. Por eso, el porcentaje de consumo anual medio por persona por este concepto disminuyó en los años 1973-1974 con respecto a 1963-1964, y otros como los transportes y comunicaciones subieron considerablemente (tabla 6)

Por tanto, no es de extrañar que la publicidad, al igual que amplía su oferta de productos, amplíe también el abanico de público al que se dirige. La misma situación de bonanza económica que supuso la llegada de multinacionales hizo que los españoles, en general, vivieran con un aceptable nivel de vida. Esto hace que las cuñas analizadas muestren una tendencia a aumentar sus miras: de un consumidor con pocos recursos a alguien que ya tiene unos ahorros para permitirse caprichos.

De todas las cuñas analizadas en esta época, se puede decir que ninguna se dirige de manera especial a un público de clase baja, ni en su argumento ni por categoría de producto. Y aunque un $75 \%$ del total no especificaba este punto, el resto sí tenía claras (si no directas) intenciones de influir en la decisión de compra de la clase alta (25\%).

Por vez primera en el análisis aparecen anuncios dirigidos a los jóvenes (14\%), desde Burger King hasta el Ministerio de Sanidad, en una campaña de prevención del alcoholismo:

El alcohol no da fuerzas. El alcohol actúa sobre el cerebro como analgésico, y oculta así la sensación de fatiga. Pero no alivia sus efectos, por lo que a la larga la fatiga aumenta. Esto lo saben muy bien los deportistas, que no consumen alcohol cuando tienen que realizar un esfuerzo. El alcohol no es la solución.

Informa el Ministerio de Sanidad y Seguridad Social.

(Década de 1970, archivo personal)

Los niños, un sector que aparecía tímidamente representado en las canciones comerciales, continuaron siendo un bajo porcentaje en este período (7\% del 


\begin{tabular}{lcc}
\hline Alimentación & 48,72 & 38,04 \\
\hline Vestuario y calzado & 14,89 & 7,70 \\
\hline Vivienda, calefacción y alumbrado & 11,02 & 14,53 \\
\hline Menaje y servicios para el hogar & 5,59 & 8,13 \\
\hline Servicios médicos y conservación de la salud & 2,48 & 2,64 \\
\hline Transportes y comunicaciones & 3,71 & 9,36 \\
\hline Esparcimiento, enseñanza y cultura & 4,31 & 7,11 \\
\hline Otros gastos & 9,28 & 12,49
\end{tabular}

Tabla 6. Porcentajes del consumo anual medio por persona de cada grupo, sobre el consumo total. Conjunto Nacional

Fuente: INE 1984, p. 316.

total), aunque refrescos como Pepsi y Mirinda ponían especial énfasis en sus beneficios para los organismos de los más pequeños.

La publicidad solamente cantada desapareció conforme se acercaba la década de los setenta. Solo 11\% de las cuñas pertenecían a esta categoría, frente a las que apoyaban su mensaje tan solo en la voz del locutor $(76 \%)$. Se empleó por primera vez un aparato electrónico llamado sintetizador en la composición de jingles. Los locutores se especializaron en publicidad conforme desaparecían las cuñas cantadas y -de las cuñas analizadas en esta etapa- nueve de cada diez eran locutadas, con predominio de una sola voz (38\%), principalmente masculina (61,8\%). También había un porcentaje pequeño, el 4\%, que incluía la locución por parte de un famoso:

Escuchen ustedes ahora al actor Arturo Fernández que nos habla del brandy Insuperable Solera Reservada de González Byass:

Las mejores cosas de la vida son siempre verdad.

Aprecie esa verdad cuando tenga una copa de brandy en la mano. Le recomiendo Insuperable, insuperable porque es verdad.

Insuperable. Porque es verdad.

(Década de 1960, archivo personal)

El mensaje en estas cuñas era directo, con muy pocos elementos distractores de la idea principal. Si se divide la muestra en géneros, más de la mitad (el 56\%) de ellas son monólogos, frente a un $12 \%$ en las que aparece un diálogo. Profundizando un poco más, los géneros más usados eran el trozo de vida (8\%), el humor (6\%) y el musical (4\%). De este modo, el esquema de la mayoría de las cuñas podría resumirse en un locutor, hablando sobre un jingle, con algún efecto que ayudase a la comprensión del mensaje.

La mejor manera de conseguir vender un producto es, sin duda, escoger acertadamente qué atributos se deben destacar. Si en la etapa anterior la escasez hacía que los atributos emocionales fueran esenciales (obtener clase y distinción bebiendo cierta marca de anís, o dejar claro ante el vecindario que uno se podía gastar un dineral en complementos para una muñeca), en esta etapa destacan los atributos físicos, que aparecen en $41 \%$ de las cuñas como único atributo. Los atributos emocionales y funcionales se encuentran en muchas menos ocasiones, un 13\% cada uno de ellos.

En la época del consumismo, del desarrollo económico, es lógico que los consumidores sean tentados por atributos físicos, pero ¿con qué tipo de argumento llegaban esos atributos a la mente del receptor? El análisis de las cuñas revela que la persuasión (60\%) seguía siendo el modo más eficaz de hacer publicidad, aunque también eran numerosos (17\%) los anuncios en los que se combinaban argumentos persuasivos e implicativos.

Las bases estaban establecidas y las cuñas publicitarias estaban, a final de esta etapa, en un estado de madurez que les permitía llegar al oyente por múltiples vías. Los recursos a su alcance eran variados, aunque encuentran una dificultad: la televisión. 


\section{CONCLUSIONES}

Las conclusiones a las que se ha llegado tras la confrontación de los resultados de la investigación social, política y económica del país a lo largo del período estudiado, así como el seguimiento de la evolución de la publicidad en prensa y radio, permiten afirmar que los medios de comunicación tradicionales, mediante su publicidad, contribuyeron de forma decisiva a la formación de hábitos de consumo y estilos de vida en los españoles del franquismo. A lo largo de este trabajo de investigación se ha destacado un buen número de piezas publicitarias que ofrecen una imagen definida de la realidad social del momento: la relación entre sexos, ideologías políticas, situación económica, hábitos de consumo y estilos de vida. También se ha visto cómo la publicidad introdujo modelos de consumo totalmente ajenos a la sociedad española, de manera que en poco tiempo fueran aceptados de forma poco traumática por la mayoría de la población.
Uno de los factores más importantes que hicieron de la publicidad un arma esencial en la creación de un modelo de consumo moderno fue la notoriedad de cada mensaje publicitario. A través de la prensa y de la radio, en un principio, y más tarde también de la televisión, los mensajes poseían una cualidad que hoy, en el estado de saturación publicitaria en el que vivimos, se ha perdido. Llamar la atención del oyente o del lector resultaba mucho más sencillo que en la actualidad. Los recursos más simples servían para permanecer en la mente del receptor.

Los productos anunciados con mayor frecuencia en prensa y radio en los primeros años de la posguerra (como puede verse en la tabla 7) eran femeninos y de clase alta: higiene personal y belleza.

Pero la imagen de la mujer en muchas otras categorías de producto es la de la ama de casa ingeniosa con soluciones para todo. Una mujer capaz de conseguir dulces o ropa nueva allí donde solo hay racionamiento
Prensa 1939-1966

Radio 1939-1959

\begin{tabular}{|c|c|c|c|c|}
\hline & Higiene y belleza & $22 \%$ & Higiene y belleza & $27,9 \%$ \\
\hline \multirow[t]{3}{*}{ Productos } & Bebidas alcohólicas & $18 \%$ & Limpieza & $19 \%$ \\
\hline & Medicinas & $9 \%$ & Almacenes & $9 \%$ \\
\hline & Alta & $74 \%$ & Sin especificar & $50 \%$ \\
\hline \multirow[t]{3}{*}{ Clase social } & Sin especificar & $26 \%$ & Baja & $39,5 \%$ \\
\hline & & & Alta & $10,5 \%$ \\
\hline & Mujeres & $42 \%$ & Mujeres & $43,6 \%$ \\
\hline \multirow[t]{3}{*}{ Público objetivo } & Hombres y mujeres & $25 \%$ & Hombre & $25,5 \%$ \\
\hline & Hombres & $23 \%$ & Hombres y mujeres & $10 \%$ \\
\hline & No aparece & $83 \%$ & No aparece & $82,7 \%$ \\
\hline \multirow[t]{3}{*}{ Precio } & Aparece precio & $14 \%$ & Aparece referencia & $15,5 \%$ \\
\hline & Aparece referencia & $3 \%$ & Aparece precio & $1,8 \%$ \\
\hline & Emocionales & $59 \%$ & Emocionales & $27,8 \%$ \\
\hline \multirow[t]{3}{*}{ Atributos } & Funcionales & $56 \%$ & Físicos & $20,4 \%$ \\
\hline & Físicos & $40 \%$ & Funcionales & $18,4 \%$ \\
\hline & Persuasivo & $64 \%$ & Persuasivo & $79,2 \%$ \\
\hline \multirow[t]{2}{*}{ Argumento } & Informativo & $30 \%$ & Implicativo & $30,1 \%$ \\
\hline & Sugestivo & $16 \%$ & Humorístico & $17,2 \%$ \\
\hline
\end{tabular}

Tabla 7. Primera etapa analizada en prensa y radio: 1939-1959/1966

Fuente: Elaboración propia. 
y enfermedades. En los años de la escasez y la autarquía esta madre avispada era capaz, con sucedáneo de café y un buen tinte, de organizar la fiesta más exitosa con sus vecinas.

Es clara la diferencia entre los productos anunciados al principio de la década de los cuarenta y aquellos que aparecen a finales de los años 1950 o principios de los 1960. En el primer caso eran habituales los anuncios de bebidas, medicinas y productos para la higiene personal y belleza, mientras que a partir de 1957-1958 se añadieron a esas categorías los electrodomésticos, las joyas y los medios de transporte. La sociedad española de los años cuarenta aprendió a convivir con la penuria. A pesar de las privaciones impuestas por la posguerra (hambre, enfermedades, racionamiento), se impuso una voluntad colectiva por sobreponerse a la adversidad. Fue una época de supervivencia, de jabón casero, medias remendadas una y mil veces y sucedáneos alimenticios.

Por eso, durante los años 1940 y 1950 se utilizó principalmente una comunicación emocional -en la que primaba la elegancia, la distinción, la exclusividad-, orientada a un público con posibilidades económicas. Entre estos atributos emocionales empleados en la posguerra hay que destacar la exaltación de lo español. Esto se encuentra en muchas de las canciones comerciales radiadas y en las páginas de los diarios nacionales. Por otro lado, y de manera muy especial en prensa, también se anunciaba un buen número de productos para una población sin posibilidades económicas, siempre presentando atributos funcionales, en anuncios en los que no solía ahorrarse texto para explicar las ventajas del uso del producto en cuanto a calidad, durabilidad, ahorro, etc. El tipo de argumentación empleada por el anunciante es persuasiva, haciendo hincapié, cuando era posible, en el porcentaje de renta que suponía la compra de un determinado producto, especialmente si era de uso frecuente.

La segunda etapa del análisis en prensa y radio coincide con un desarrollo económico que hace que aparezcan en el mercado más productos listos para establecer nuevos estilos de vida. Gracias a su publicidad, las personas empezaron a desear artículos de los que, hasta hacía muy poco, ni siquiera conocían su existencia. De esta manera, nuevos productos ofrecían nuevos hábitos de consumo, lo que a su vez se tradujo en nuevos estilos de vida.

Las categorías de productos se multiplicaron, aparecieron medios de transporte, joyas, bebidas sin alcoholy alimentación entre otras, como puede verse en la tabla 8).
La publicidad cambia para facilitar la llegada de nuevos productos y servicios, que aprovecharon la mejora económica general que vivía el país en esos años. Las marcas aumentaron y se diversificaron, los artículos se encuadraron por primera vez en universos simbólicos y motivacionales diferentes. Es curioso observar cómo en prensa se anunciaban joyas, mientras que en radio hablaban de alimentación. Esto es debido, en parte, al carácter un tanto elitista de la prensa, mientras que el consumo de radio era más popular. El análisis demuestra una evolución de la publicidad hacia la democratización de los atributos. Se empleaban todos o ninguno (como en el sorprendente caso de la radio, donde el modelo de muchas cuñas se limita a hacer una gracia sin relación con el producto, para nombrar a continuación la marca). La publicidad en prensa, por ejemplo, muestra un equilibrio en el uso de atributos emocionales y físicos. Era la época del consumismo, del desarrollo económico, por lo que es lógico que los consumidores fueran tentados por atributos físicos con toques psicológicos (el coche más elegante hace más elegante a su dueño, en una relación que llevada al extremo freudiano se traduce en que el coche más potente hace más potente a su dueño). En cuanto al tipo de argumento empleado por la publicidad en todas las épocas y en todos los medios, destaca el uso de la comunicación persuasiva.

Los productos anunciados son un reflejo fiel del cambio social que se vivía en España. La forma de vender cambió. Los argumentos evolucionaron, se refinaron. La publicidad presentaba por adelantado una realidad social que estaba por llegar, pero que aún no se vivía en el país por lo que, de alguna manera, no dejaba de mostrar una fantasía que resultaba ser un reflejo más fiel al estilo de vida americano que al español.

\section{DISCUSIÓN}

Esta investigación analiza cómo los medios de comunicación seleccionados, prensa y radio, mediante su publicidad, contribuyeron de forma decisiva a la formación de hábitos de consumo y estilos de vida en los españoles del franquismo, dando paso a la sociedad de consumo.

Los resultados del estudio muestran cómo la notoriedad de cada mensaje publicitario llega al consumidor a través de unos atributos cada vez más emocionales con argumentaciones persuasivas. Se muestra claramente la diferenciación de clases sociales, con la aparición de nuevos productos que dieron lugar a nuevos 
Prensa 1967-1975

Radio 1960-1975

\begin{tabular}{|c|c|c|c|c|}
\hline & Joyas & $20 \%$ & Bebidas sin alcohol & $18 \%$ \\
\hline \multirow[t]{2}{*}{ Productos } & Medios transporte & $14 \%$ & Alimentación & $17 \%$ \\
\hline & Bebidas alcohólicas & $11 \%$ & Medios transporte & $12 \%$ \\
\hline \multirow{2}{*}{ Clase social } & Alta & $62 \%$ & Sin especificar & $75 \%$ \\
\hline & Sin especificar & $38 \%$ & Alta & $25 \%$ \\
\hline \multirow{3}{*}{ Público objetivo } & Hombres y mujeres & $38 \%$ & Hombres & $33 \%$ \\
\hline & Hombres & $33 \%$ & Mujeres & $24 \%$ \\
\hline & Mujeres & $25 \%$ & Hombres y mujeres & $15 \%$ \\
\hline \multirow{3}{*}{ Precio } & No aparece & $73 \%$ & No aparece & $84 \%$ \\
\hline & Aparece precio & $16 \%$ & Aparece referencia & $10 \%$ \\
\hline & Aparece referencia & $11 \%$ & Aparece precio & $6 \%$ \\
\hline \multirow{3}{*}{ Atributos } & Físicos & $56 \%$ & Físicos & $29 \%$ \\
\hline & Emocionales & $53 \%$ & No aparecen & $15 \%$ \\
\hline & Funcionales & $39 \%$ & Funcionales & $11 \%$ \\
\hline \multirow{3}{*}{ Argumento } & Sugestivo & $47 \%$ & Persuasivo & $83 \%$ \\
\hline & Persuasivo & $39 \%$ & Implicativo & $22 \%$ \\
\hline & Informativo & $31 \%$ & Humorístico & $14 \%$ \\
\hline
\end{tabular}

Tabla 8. Segunda etapa analizada en prensa y radio: 1960/1967-1975

Fuente: Elaboración propia.

hábitos de consumo y, por lo tanto, a nuevos estilos de vida. La publicidad cambió para adaptarse a los nuevos productos, y lar marcas aumentaron y se diversificaron, lo que dio lugar a universos simbólicos diferentes.

Los españoles del período estudiado eran consumidores adultos en una sociedad con un modelo de consumo desigual, en el que la publicidad juega un papel fundamental de cohesión social, y los ciudadanos pasan a comprar productos no por sus posibilidades o prestaciones, sino por lo que significan. Estos resultados coinciden con los encontrados en Alonso y Conde (1994), Castillo (1987) y López (1994) sobre el consumo y la publicidad.

Aunque este estudio es relevante al realizar un análisis descriptivo exhaustivo del material publicitario objeto de estudio, y de los criterios para la clasificación del material analizado, no está exento de limitaciones. En primer lugar, solo analiza la publicidad en prensa y en radio, por lo que la televisión no aparece, y sería relevante para ampliar y reforzar la investigación. Se espera que futuras investigaciones puedan abarcar estas carencias y mostrar nuevos resultados. Asimismo, sería interesante comparar si en Iberoamérica en este mismo período (1939-1975) la publicidad en los medios de comunicación contribuyó a la formación de hábitos de consumo y estilos de vida en la sociedad, y qué diferencias existen con la española. El desafío sería poder mostrar estas diferencias en los distintos países y ver qué repercusiones tuvieron en la sociedad del momento. 


\section{AGRADECIMIENTOS}

La recopilación de las canciones comerciales de los años 1930-1950 ha sido posible gracias a la Cámara de Comercio e Industria de Madrid. El material de las décadas de 1960 y 1970 se lo debo agradecer especialmente a Guillermo Barea, de la Cadena Ser, gracias a quien he podido disponer del que, probablemente, sea el único material conservado de la década de los sesenta. El resto de las cuñas han sido recogidas gracias a distintos profesionales, que han mostrado una amabilidad extrema al permitir que realizara copias para el análisis, ya que las conservaban a título personal. Agradezco también a la Hemeroteca Nacional, por autorizarme el acceso a los periódicos de la época estudiada, y a todos los entrevistados por su tiempo, por compartir sus vivencias conmigo y así poder aprender más sobre el período estudiado.

Agradezco a los tres revisores anónimos sus valiosos comentarios y sugerencias para mejorar este artículo y así convertirlo en una aportación más relevante y conferirle una proyección académica más amplia entre los trabajos relacionados con el objeto de estudio.

\section{REFERENCIAS}

AAVV. (1993). Antología de las canciones publicitarias de los años 30, 40 y 50 [Anthology of the advertising songs of the 30's, 40's and 50's]. Madrid: Cámara de Comercio e Industria de Madrid.

Abella, R. (1985). Vida cotidiana bajo el régimen de Franco [Daily life under Franco`s regime]. Barcelona: Argos Vergara.

Abella, R. (1990). La vida cotidiana en la España de los 60 [The daily life in the Spain of the 60's]. Madrid: Prado.

Alonso, L. E. \& Conde, F. (1994). Historia del consumo en España: Una aproximación a sus orígenes y primeros desarrollos [History of consumption in Spain: An approach to its origins and first developments]. Madrid: Debate.

Andrés Orizo, F. (1968). La evolución del consumo en España [The evolution of consumption in Spain] Control, 69, 39.

Andrés Orizo, F. (1977). Las bases sociales del consumo y del ahorro en España [The social bases of consumption and saving in Spain]. Madrid: Confederación Española de Cajas de Ahorros.

Asociación para la Investigación de Medios de Comunicación (1998). Estudio General de Medios (EGM) (1968-1998) [General Media Survey (EGM) (1968-1998)]. Todos los medios de comunicación social. EGM 30 [All social media. EGM 30].

Barea, P. (1994). La estirpe de Sautier. La época dorada de la radionovela en España (1924-1964) [The strain of Sautier. The golden age of the soap opera in Spain (1924-1964)]. Madrid: El País S.A/Aguilar S.A.

Barrera del Bario, C. (1992). Historia del periodismo Español [History of Spanish journalism]. Pamplona: Universidad de Navarra S.A.

Baudrillard, J. (2009[1970]). La sociedad de consumo. Sus mitos, sus estructuras [The consumption society. Its myths, its structures]. Madrid: Siglo XXI de España.

Caro, A. (2014). Comprender la publicidad para transformar la sociedad [Understanding advertising to transform society]. Cuadernos.info, (34), 39-46. https://doi.org/10.7764/cdi.34.584

Castillo, J. (1987). Sociedad de consumo a la española [Consumption society at the Spanish style]. Madrid: Eudema.

Conde, F. (1994). Notas sobre la génesis de la sociedad de consumo en España [Notes on the genesis of the consumer society in Spain]. Politica y Sociedad, 16, 135-148. Retrieved from http://revistas.ucm.es/ index.php/POSO/article/view/POSO9494120135A/30291 
De Miguel, A. (1973, August 18). Somos europeos, pero menos [We are European but less] $A B C$, p. 25. Retrieved from http://hemeroteca.abc.es/nav/Navigate.exe/hemeroteca/madrid/ blanco.y.negro/1973/08/18/025.html

Dirección General de Estadísticas. (1943). Remuneraciones máximas por jornada. Salarios [Maximum remuneration per day. Wages]. In Anuario Estadístico de España [Statistical Yearbook of Spain], (p. 1179). Madrid: Presidencia del Consejo de Ministros. Dirección General del Instituto Geográfico Catastral y de Estadística.

Eguizábal Maza, R. (2007). Teoría de la publicidad [Advertising Theory]. Madrid: Cátedra.

González Martín, J. A. (1996). Teoría General de la Publicidad [General Theory of Advertising]. Madrid: Fondo de Cultura Económica.

Instituto Nacional de Estadística (INE). (1955). Remuneraciones máximas por jornada [Maximum pay per day]. In Anuario Estadístico de España [Statistical Yearbook of Spain], (p. 524). Madrid: Presidencia del Consejo de Ministros. Dirección General del Instituto Geográfico Catastral y de Estadística.

Instituto Nacional de Estadísticas (INE). (1960). Coste de la vida en las capitales [Cost of living in capitals]. In Anuario Estadístico de España [Statistical Yearbook of Spain], (p. 598). Madrid: Presidencia del Consejo de Ministros. Dirección General del Instituto Geográfico Catastral y de Estadística.

Instituto Nacional de Estadísticas (INE). (1965). Estadísticas de salarios [Wage statistics]. In Anuario Estadístico de España [Statistical Yearbook of Spain], (p. 292). Madrid: Presidencia del Consejo de Ministros. Dirección General del Instituto Geográfico Catastral y de Estadística.

Instituto Nacional de Estadísticas (INE). (1970a). Remuneraciones máximas por jornada [Maximum pay per day]. In Anuario Estadístico de España [Statistical Yearbook of Spain], (p. 285). Madrid: Presidencia del Consejo de Ministros. Dirección General del Instituto Geográfico Catastral y de Estadística.

Instituto Nacional de Estadística (INE). (1970b). Censo de las viviendas en España [Census of housing in Spain]. In Anuario Estadístico de España [Statistical Yearbook of Spain], (p. 55). Madrid: Presidencia del Consejo de Ministros. Dirección General del Instituto Geográfico Catastral y de Estadística.

Instituto Nacional de Estadística (INE). (1975) Encuesta de presupuestos familiares Equipamientos y condiciones de las viviendas familiares [Family budget survey Household equipment and conditions]. In Anuario Estadístico de España [Statistical Yearbook of Spain], (p. 86). Madrid: Presidencia del Consejo de Ministros. Dirección General del Instituto Geográfico Catastral y de Estadística.

Instituto Nacional de Estadística (INE). (1978). Partida de gasto de los hogares españoles [Expenditure item of Spanish households]. In Anuario Estadístico de España [Statistical Yearbook of Spain], (p. 308) Madrid: Presidencia del Consejo de Ministros. Dirección General del Instituto Geográfico Catastral y de Estadística.

Instituto Nacional de Estadística (INE) (1984). Encuesta de presupuestos familiares [Family Budget Survey]. In Anuario Estadístico de España [Statistical Yearbook of Spain], (p. 316). Madrid: Presidencia del Consejo de Ministros. Dirección General del Instituto Geográfico Catastral y de Estadística.

López Vargas, Ma . L. (1994). El hombre y la cosmética: el modelo de consumo tradicional al modelo de consumo moderno [The man and the cosmetics: the model of traditional consumption to the model of modern consumption]. Politica y Sociedad, 16, 201-209. Retrieved from https://revistas.ucm.es/ index.php/POSO/article/view/POSO9494120201A/30313

Marchamalo, J. (1996). Bocadillos de Delfín [Dolphin Snacks]. Barcelona: Grijalbo.

Martín Requero, Mª I. (2002). Consumo y publicidad en la España del primer tercio del siglo XX [Consumption and advertising in Spain in the first third of the 20th century]. Publifilia, (6), 37-48.

Montero, M. (2012). La publicidad española durante el franquismo (1939-1975). De la autarquia al consumo [Spanish advertising during the Franco regime (1939-1975). From Autarchy to Consumerism]. Hispania, Revista Española de Historia, 72(240), 205-232. https://doi.org/10.3989/hispania.2012.v72.i240.369 
Morodo, R. (1966). De la Ley de Prensa a la Reforma Constitucional en España [From the Press Law to the Constitutional Reform in Spain]. Cuadernos para el Diálogo, 32, 12.

Pérez Ruíz, M. A. (2001). La publicidad en España. Anunciantes, agencias y medios. 1850-1950 [Advertising in Spain. Advertisers, agencies and media. 1850-1950]. Madrid: Fragua.

Pérez Ruíz, M. A. (2003). La transición de la publicidad en España. Anunciantes, agencias y medios. 19501980 [The transition of advertising in Spain. Advertisers, agencies and media. 1950-1980]. Madrid: Alfaguara.

Vázquez Montalbán, M. (1986). Crónica sentimental de España [Sentimental chronicle of Spain]. Madrid: Espasa Calpe.

Ana Sebastián Morillas, doctora en Comunicación Audiovisual y Publicidad, profesora de la Facultad de Ciencias Sociales, Jurídicas y de la Comunicación de la UVA (Campus de Segovia). Imparte docencia en programas de grado y posgrado. Sus principales líneas de investigación están relacionadas con la planificación estratégica de marca, la publicidad, la comunicación, y el marketing. Ha sido fellow del RCC en la Universidad de Harvard (Cambridge, Masachusetts). Forma parte del grupo de investigación Gestión de las marcas y procesos de comunicación. 